Article

\title{
Dual Emission in a Ligand and Metal Co-Doped Lanthanide-Organic Framework: Color Tuning and Temperature Dependent Luminescence
}

\author{
Despoina Andriotou ${ }^{1}$, Stavros A. Diamantis ${ }^{1}$, Anna Zacharia ${ }^{2}$, Grigorios Itskos ${ }^{2}$, \\ Nikos Panagiotou ${ }^{3}$, Anastasios J. Tasiopoulos ${ }^{3}(\mathbb{D})$ and Theodore Lazarides ${ }^{1, *}$ \\ 1 Department of Chemistry, Aristotle University of Thessaloniki, 54124 Thessaloniki, Greece; \\ despoina.andriotou95@gmail.com (D.A.); sdiamant@chem.auth.gr (S.A.D.) \\ 2 Department of Physics, University of Cyprus, 1687 Nicosia, Cyprus; zacharia.anna@ucy.ac.cy (A.Z.); \\ itskos@ucy.ac.cy (G.I.) \\ 3 Department of Chemistry, University of Cyprus, 1687 Nicosia, Cyprus; panagiotou.nikos@ucy.ac.cy (N.P.); \\ atasio@ucy.ac.cy (A.J.T.) \\ * Correspondence: tlazarides@chem.auth.gr; Tel.: +30-2310-997853
}

Received: 1 December 2019; Accepted: 15 January 2020; Published: 25 January 2020

\begin{abstract}
In this study, we report the luminescence color tuning in the lanthanide metal-organic framework (LnMOF) ([La(bpdc)Cl(DMF)] (1); bpdc ${ }^{2-}=\left[1,1^{\prime}\right.$-biphenyl $]-4,4^{\prime}$-dicarboxylate, DMF = $\mathrm{N}, \mathrm{N}$-dimethylformamide) by introducing dual emission properties in a $\mathrm{La}^{3+} \mathrm{MOF}$ scaffold through doping with the blue fluorescent 2,2'-diamino-[1,1'-biphenyl]-4,4'-dicarboxylate (dabpdc ${ }^{2-}$ ) and the red emissive $\mathrm{Eu}^{3+}$. With a careful adjustment of the relative doping levels of the lanthanide ions and bridging ligands, the color of the luminescence was modulated, while at the same time the photophysical characteristics of the two chromophores were retained. In addition, the photophysical properties of the parent MOF (1) and its doped counterparts with various dabpdc ${ }^{2-} / \mathrm{bpdc}^{2-}$ and $\mathrm{Eu}^{3+} / \mathrm{La}^{3+}$ ratios and the photoinduced energy transfer pathways that are possible within these materials are discussed. Finally, the temperature dependence study on the emission profile of a doped analogue containing $10 \%$ dabpdc $^{2-}$ and $2.5 \% \mathrm{Eu}^{3+}(7)$ is presented, highlighting the potential of this family of materials to behave as temperature sensors.
\end{abstract}

Keywords: metal-organic frameworks; luminescence; lanthanides; color tuning; doping; temperature sensors

\section{Introduction}

The unique luminescence properties of trivalent lanthanide ions $\left(\mathrm{Ln}^{3+}\right)$, including sharp atomic-like emission spectra, which are largely independent of the metal's coordination environment and long lifetimes, reaching the order of a few milliseconds in the cases of $\mathrm{Eu}^{3+}$ and $\mathrm{Tb}^{3+}$, make them well suited as luminophores for a diverse range of applications spanning the fields of biotechnology, telecommunications, sensors and lighting [1-4]. Despite their favorable properties, the Laporte forbidden nature of $\mathrm{f}-\mathrm{f}$ transitions makes luminescence through direct excitation of $\mathrm{Ln}^{3+}$ ions extremely inefficient. However, this shortcoming can be tackled through the coordination of $\mathrm{Ln}^{3+}$ ions to strongly absorbing chromophores which act as antennae by sensitizing metal-based emission through photoinduced energy transfer [5]. Recently, a considerable amount of research effort has been directed towards the development of lanthanide ratiometric thermometers [6] which are based on the temperature-induced changes in the photophysical behavior of at least two emission centers, thereby providing a more reliable and accurate self-referenced signal with reduced dependence on the experimental conditions. The majority lanthanide luminescent thermometers reported in the literature 
are based on measuring the ratio between the emission intensities of $\mathrm{Tb}^{3+}$ and $\mathrm{Eu}^{3+}$ centers at different temperatures [7-10] while those that involve the emission of a bridging ligand [11] or an encapsulated organic dye [12] are relatively rare.

In this contribution, we report the preparation and study of a homologous series of ligand and metal co-doped lanthanide-organic frameworks where a parent framework [ $\mathrm{La}(\mathrm{bpdc}) \mathrm{Cl}(\mathrm{DMF})]$ (1) [13] is doped with the strongly fluorescent diamino derivative of the $\mathrm{bpdc}^{2-}$ bridging ligand dabpdc ${ }^{2-}$ and with the luminescent lanthanide ion $\mathrm{Eu}^{3+}$. The lanthanide MOF (LnMOF) ([La(bpdc)Cl(DMF)] (1) was chosen as a doping platform because: (i) its highly reproducible synthesis and chemical robustness, as dry crystals of $\mathbf{1}$ can be left in air for several months without showing any sign of deterioration; (ii) the bpdc ${ }^{2-}$ bridging ligand has been demonstrated to be a good sensitizer for the luminescence of the $\mathrm{Eu}^{3+}$ ion [14-16]; (iii) the possibility to obtain strong $\mathrm{Ln}^{3+}$-based emission due to the absence of water from the coordination sphere of the $\mathrm{Ln}^{3+}$ ion which would provide an efficient non-radiative deactivation pathway for $\mathrm{f}-\mathrm{f}$ excited states through vibrational coupling with $\mathrm{O}-\mathrm{H}$ oscillators [17]. Thus, following the above mentioned doping procedure, we prepared an isostructural series of materials with the formula $\left[\mathrm{La}_{1-\mathrm{x}} \mathrm{Eu}_{\mathrm{x}}(\mathrm{bpdc})_{1-\mathrm{y}}(\mathrm{dabpdc})_{\mathrm{y}} \mathrm{Cl}(\mathrm{DMF})\right](\mathrm{x}=0-0.025 ; \mathrm{y}=0$ or 0.1$)$ which show emission from both chromophores. With careful adjustment of the $\mathrm{Eu}^{3+}$ doping percentage while keeping the dabpdc ${ }^{2-}$ doping level at $10 \%$, luminescence color tuning from blue to red through purple was achieved. In addition, a temperature dependent luminescence study of material $7(x=0.025 ; y=0.1)$ shows that good temperature sensing action can be obtained in the region from 80 to $180 \mathrm{~K}$ with the sensitivity parameter reaching the maximum value $2.51 \% \mathrm{~K}^{-1}$ at $80 \mathrm{~K}$.

\section{Results and Discussion}

\subsection{Synthesis and Structural Studies}

The reaction of the bridging ligand $\mathrm{H}_{2}$ bpde with $\mathrm{LaCl}_{3} \cdot \mathrm{xH}_{2} \mathrm{O}$ in a 1:1 molar ratio in DMF at $110^{\circ} \mathrm{C}$, afforded a crystalline product $\mathbf{1}$ with the formula $[\mathrm{La}(\mathrm{bpdc}) \mathrm{Cl}(\mathrm{DMF})]$ which is isostructural to the compound of the same formula reported by Hou et al. in 2013 [13]. Compound 1 crystallizes in the orthorombic Pnma space group and features one crystallographically unique lanthanum cation with a coordination number of nine while its coordination polyhedron can be best described as a tricapped trigonal prism. As seen in Figure 1, the structure of $\mathbf{1}$ features an infinite rod secondary building unit (SBU) consisting of a zig-zag chain of $\mathrm{La}^{3+}$ ions bridged by $\mu_{2} \mathrm{Cl}^{-}$anions and by $\mu_{2}-\eta^{2}: \eta^{1}$ carboxylate units. Each bridging ligand is connected to two different chains, thus forming a three-dimensional framework with rhombic channels along the crystallographic axis which are occupied by terminally coordinated DMF molecules displaying two-fold positional disorder around the crystallographic mirror plane. Selected bond lengths and bond angles for $\mathbf{1}$ are listed in Supplementary Table S1.

In agreement with the findings of Hou et al. [13], frameworks isostructural to $\mathbf{1}$ could only be obtained with early lanthanide ions such as $\mathrm{La}^{3+}, \mathrm{Pr}^{3+}$ and $\mathrm{Nd}^{3+}$ while our attempts to prepare a luminescent $\mathrm{Eu}^{3+}$ analog of $\mathbf{1}$ were met with failure. We therefore decided to follow the strategy of metal doping in order to introduce the luminescent $\mathrm{Eu}^{3+}$ ion within the framework of $\mathbf{1}$. Thus, a series of reactions in the presence $1-2.5 \mathrm{~mol} \%$ of $\mathrm{Eu}^{3+}$ afforded crystalline products $2-9$ which are isostructural to $\mathbf{1}$, as confirmed by powder X-ray diffraction (pxrd) studies (Figure 2). The $\mathrm{Eu}^{3+}$ doped materials displayed the characteristic red luminescence of the $\mathrm{Eu}^{3+}$ ion upon being illuminated with a standard laboratory UV lamp (vide infra) thus showing that $\mathrm{Eu}^{3+}$ is successfully incorporated within the parent structure. This observation encouraged us to attempt further doping of the parent framework with the intensely blue fluorescent diamino derivative the $\mathrm{H}_{2}$ bpdc bridging ligand 2,2'-diamino-[1, $1^{\prime}$-biphenyl]-4,4'-dicarboxylic acid $\left(\mathrm{H}_{2}\right.$ dabpdc). Indeed, we found that the presence of up to $33 \mathrm{~mol} \%$ of $\mathrm{H}_{2}$ dabpdc in the initial reaction mixture leads to crystalline products which are isostructural to $\mathbf{1}$ (Figure 2). In order to gain better insight on the degree of incorporation of dabpdc $^{2-}$ within the parent framework of $\mathbf{1}$, we subjected a sample of $\mathbf{2}\left(0 \mathrm{~mol} \% \mathrm{Eu}^{3+}\right.$ and $10 \mathrm{~mol} \%$ of $\mathrm{H}_{2}$ dabpdc in the reaction feed) to ${ }^{1} \mathrm{H}-\mathrm{NMR}$ analysis after it was digested in a mixture of $\mathrm{D}_{2} \mathrm{O} / \mathrm{NaOH}$. 
From the ratio of the peak integrals corresponding to bpdc ${ }^{2-}$ and dabpdc ${ }^{2-}$ (Supplementary Figure S1), we calculated a molar fraction of $12 \%$ of $\mathrm{dabpdc}^{2-}$ within 2 which is close to the molar percentage of dabpdc ${ }^{2-}$ present in the reaction feed. This finding suggests that, in the employed experimental conditions, dabpdc ${ }^{2-}$ is similar to $\mathrm{bpdc}^{2-}$ in terms of reactivity towards $\mathrm{La}^{3+}$ and at least relatively low percentages of dabpdc ${ }^{2-}$ in the reaction feed result in a statistical distribution of the amino substituted bridging ligand within the product.

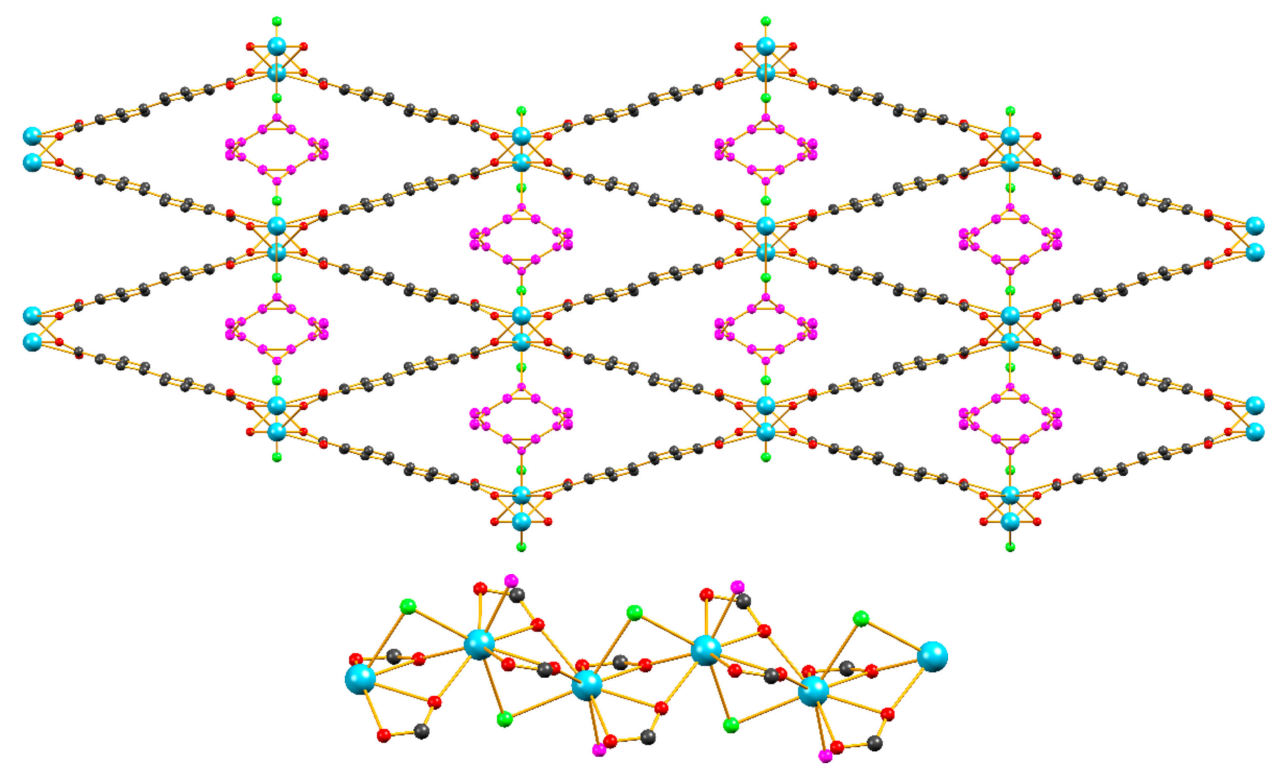

Figure 1. The crystal structure of the parent framework 1 [13] viewed along the a axis. The infinite rod metal SBU of $\mathbf{1}$ is shown below the main structure. Color code: Lanthanum: turqoise, Carbon: black, Oxygen: red, Chlorine: green. The atoms of the coordinated DMF molecules are shown in magenta.

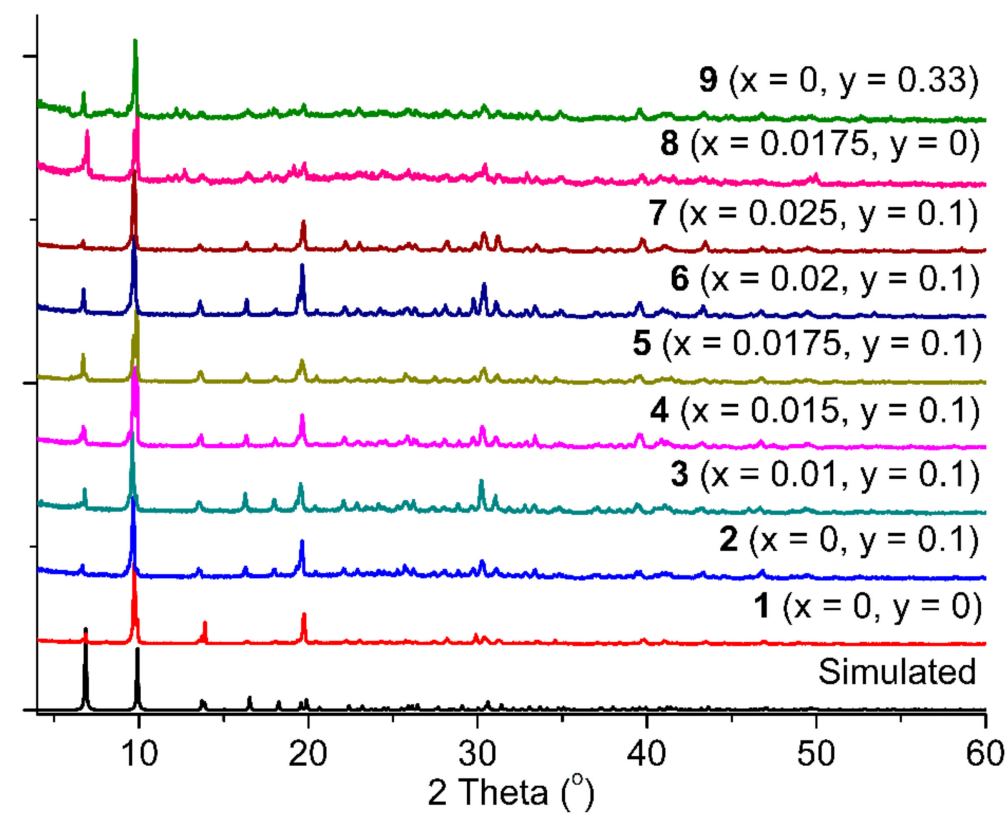

Figure 2. Powder $X$-ray diffraction paterns of the doped analogues 1-9 with the general formula $\left[\mathrm{La}_{1-\mathrm{x}} \mathrm{Eu}_{\mathrm{x}}(\mathrm{bpdc})_{1-\mathrm{y}}(\mathrm{dabpdc})_{\mathrm{y}} \mathrm{Cl}(\mathrm{DMF})\right]$; the values of $\mathrm{x}$ and $\mathrm{y}$ corresponding to each doped analogue are shown on the graph. 
In addition to the ${ }^{1} \mathrm{H}-\mathrm{NMR}$ study, we carried out single crystal $\mathrm{X}$-ray structural analysis on a sample of $9\left(0 \mathrm{~mol} \% \mathrm{Eu}^{3+}\right.$ and $33 \mathrm{~mol} \%$ of $\mathrm{H}_{2}$ dabpdc in the reaction feed). Crystal and refinement data can be found in Supplementary Table S2. The overall structure of $\mathbf{9}$ is virtually identical to that of $\mathbf{1}$ with the difference that the bridging ligand shows significantly greater disorder and had to be refined in two positions (Figure 3). We were also able to locate one of the two nitrogen atoms of dabpdc ${ }^{2-}$ which $^{2}$ refined well with a given site occupancy of ca. 17\%. In addition, several constraints were applied in order to keep the $\mathrm{C}-\mathrm{N}$ distance and the angles around the $\mathrm{C}-\mathrm{N}$ bond within chemically acceptable values. The disorder of the bridging ligand in 9 is possibly a result of the different conformations adopted by bpdc ${ }^{2-}$ and dabpdc ${ }^{2-}$. In the parent compound 1 , the bpdc ${ }^{2-}$ ligand adopts a conformation where the two phenylene groups of the biphenyl spacer are virtually co-planar [13] a feature that is commonly found in structures containing the bpdc ${ }^{2-}$ ligand [18-26] while, as observed by us [27] and others [28], the dabpdc ${ }^{2-}$ bridging ligand tends to adopt a staggered syn conformation where the dihedral angle between the two phenylene groups is in the order of $60-70^{\circ}$. It is therefore reasonable to expect that the presence of about one third dabpdc ${ }^{2-}$ at the sites normally occupied by bpdc ${ }^{2-}$ in the parent framework would induce some additional disorder to the diphenylene spacer. Consequently the ${ }^{1} \mathrm{H}-\mathrm{NMR}$ and crystallographic data indicate that even though the dabpdc ${ }^{2-}$ moiety seems to have slightly different stereochemical demands than the bpdc ${ }^{2-}$ ligand of the parent framework, its incorporation does not induce a big distortion to the overall structure.

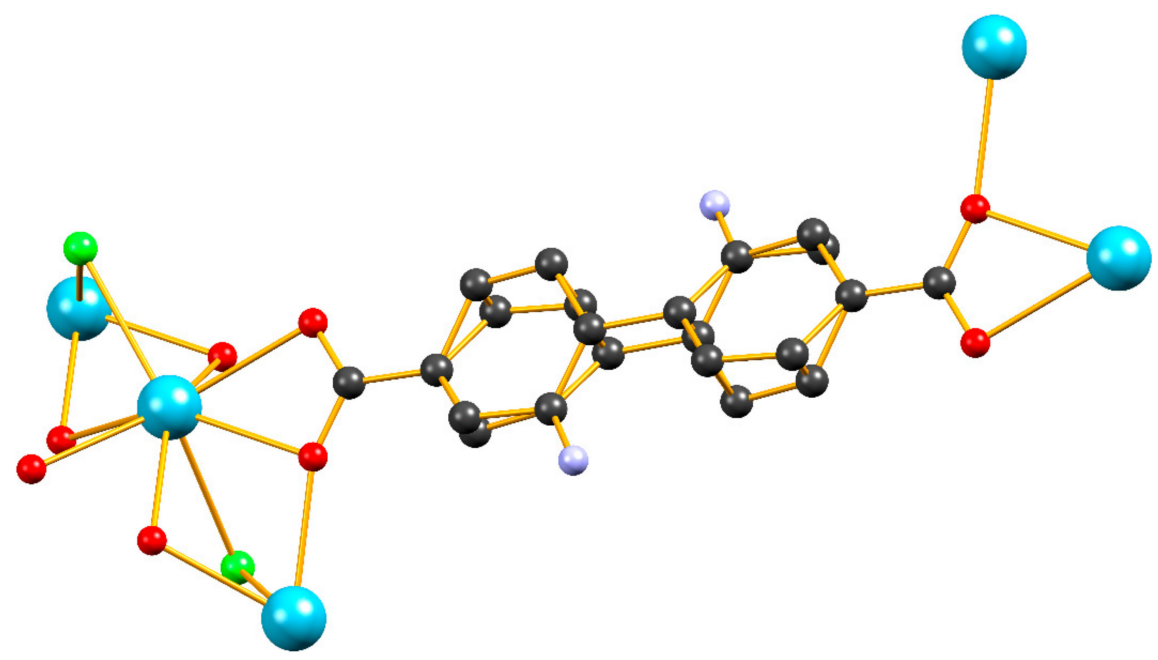

Figure 3. Partial view of the crystal structure of $\mathbf{9}$ highlighting the disorder of the biphenyl bridging unit. The nitrogen atoms were refined with a site occupancy of ca. 17\%. Hydrogen atoms and the coordinated DMF molecules are omitted for clarity. Color code: Lanthanum: turqoise, Carbon: black, Oxygen: red, Nitrogen: blue, Chlorine: green.

\subsection{Thermogravimetric Analysis}

The thermal stability of 1, 2 and $\mathbf{6}$ was studied by thermogravimetric analysis (TGA) under air (see Supplementary Figures S2 and S3). All the analogues show essentially identical behavior and for this reason only the thermograph of $\mathbf{6}$ (Figure 4) shall be discussed. In particular, the weight loss in 6 was observed in two steps. The first step is observed in the temperature range $240-330{ }^{\circ} \mathrm{C}$ and the corresponding weight loss is attributed to the coordinated DMF molecules (experimental loss: 16.83\%, theoretically estimated loss of $14.9 \%$ ). The framework remains thermally stable up to $\sim 500{ }^{\circ} \mathrm{C}$ and then the second mass loss step appears, corresponding to the decomposition of the framework, which is completed up to $\sim 525^{\circ} \mathrm{C}$. 


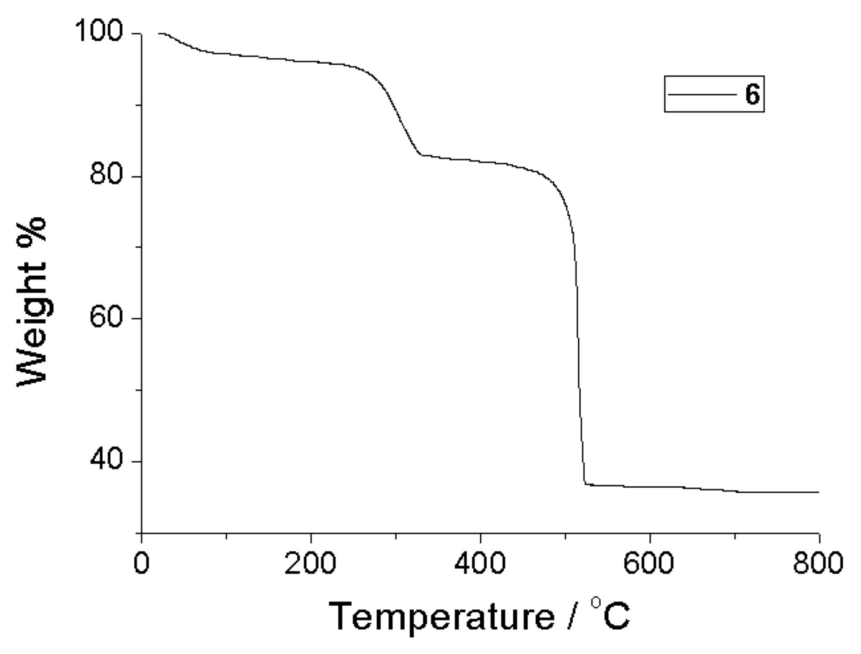

Figure 4. The TGA curve of compound 6.

\subsection{Luminescence Properties}

Photophysical studies on microcrystalline powders of the parent framework $\mathbf{1}$ and its metal and ligand doped counterparts were carried out by emission spectroscopy. Excitation of compound 1 at $\lambda_{\text {exc }}$ $=365 \mathrm{~nm}$ gives rise to a fluorescence band with maximum at ca. $440 \mathrm{~nm}$ (Figure 5), which is attributed to the radiative deactivation of the lowest energy ${ }^{1} \pi-\pi^{*}$ excited state of the bpdc ${ }^{2-}$ bridging ligand $[13,14]$. The excitation spectrum of $\mathbf{1}$ (monitored at $450 \mathrm{~nm}$ ) shows that the lowest energy absorption feature is at $375 \mathrm{~nm}$ and tails off rapidly after $400 \mathrm{~nm}$, thereby showing virtually no absorption in the visible region (Figure 5). When the parent framework of $\mathbf{1}$ is doped $10 \mathrm{~mol} \%$ with the diamino derivative dabpdc $^{2-}(2)$, a rather small red shift in the fluorescence peak which maximizes at ca. $463 \mathrm{~nm}$ was observed. Based on a comparison with our previous work on the fluorescence properties of $\mathrm{Ca}^{2+}$ and $\mathrm{Sr}^{2+}$ MOFs featuring $\left(\mathrm{NH}_{2}\right)_{2} \mathrm{bpdc}^{2-}$ as bridging ligand, we attribute the red shifted emission signal of 2 predominantly to the fluorescence from the dabpdc ${ }^{2-}$ chromophore [27]. From the onsets of the emission peaks of the two chromophores in $\mathbf{1}$ and $\mathbf{2}$ the energies of the lowest lying ${ }^{1} \pi-\pi^{*}$ of excited states of bpdc ${ }^{2-}$ and dabpdc ${ }^{2-}$ were estimated at ca. 25,000 and $23,500 \mathrm{~cm}^{-1}$ respectively [29]. It therefore follows that initial excitation of predominantly the bpdc ${ }^{2-}$ moiety of $\mathbf{2}$ (mainly due to its much higher abundance within the material's framework) is followed by energy transfer to the dabpdc ${ }^{2-}$ chromophore most possibly through a mechanism involving exciton diffusion to a position adjacent to a dabpdc ${ }^{2-}$ group and subsequent coulombic (Förster) energy transfer to the latter [30-34]. It is important to mention that the emission profiles of samples doped with significantly larger percentages of dabpdc ${ }^{2-}$ (such as sample 9) are virtually identical to that of 2 , thus confirming that in the latter material interchromophore energy transfer reaches its maximum efficiency.

The emission spectrum of compound $8\left(\lambda_{\text {exc }}=365 \mathrm{~nm}\right)$, where the parent framework of 1 is doped only with $1.75 \mathrm{~mol} \% \mathrm{Eu}^{3+}$, is dominated by the $\mathrm{Eu}^{3+}$-based ${ }^{5} \mathrm{D}_{0} \rightarrow{ }^{7} \mathrm{~F}_{J}(J=0-4)$ emission peaks which are located at 580, 596, 620, 654 and $704 \mathrm{~nm}$ respectively. On the high energy region of the spectrum, we observe the relatively weak residual emission of the $\mathrm{bpdc}^{2-}$ bridging ligand which maximizes at ca. $440 \mathrm{~nm}$ indicating that, even at this relatively low doping level of $1.75 \mathrm{~mol} \%$, ligand-to-Eu ${ }^{3+}$ energy transfer is quite efficient $[1,35]$. The fact that the bpdc ${ }^{2-}$ bridging ligand is a good sensitizer for both dabpdc ${ }^{2-}$ and $\mathrm{Eu}^{3+}$ prompted us to synthesize and study frameworks where both energy acceptors are present within the parent framework of $\mathbf{1}$. 


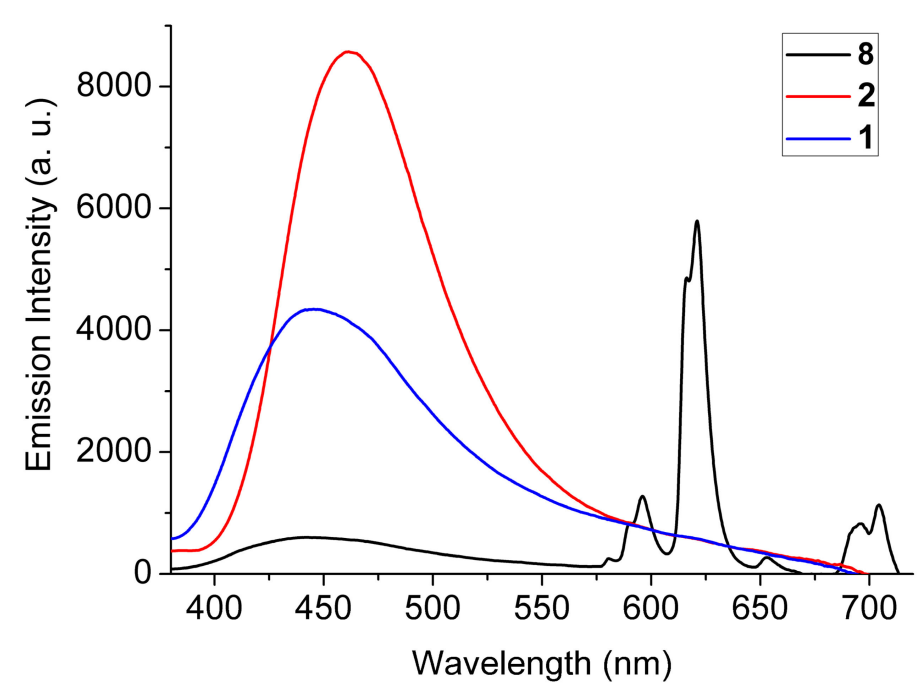

Figure 5. The solid-state emission spectra of compounds 1, 2 and 8 upon excitation at $365 \mathrm{~nm}$. See main text for details.

In the case of $\mathbf{6}$, where both dabpdc ${ }^{2-}$ and $\mathrm{Eu}^{3+}$ are doped into the parent framework of $\mathbf{1}$, excitation at $365 \mathrm{~nm}$ results in emission from both the amino substituted organic chromophore and the luminescent lanthanide ion (Figure 6). The maxima of the ${ }^{5} \mathrm{D}_{0} \rightarrow{ }^{7} \mathrm{~F}_{J}(J=0-4)$ peaks of Eu ${ }^{3+}$ in 6 are in the expected positions while the fluorescence from the dabpdc ${ }^{2-}$ chromophore occupies the blue region of the spectrum showing a maximum at ca. $470 \mathrm{~nm}$ (vide supra). The excitation spectra of 6 were measured monitoring at both the ligand $(470 \mathrm{~nm})$ and $\mathrm{Eu}^{3+}(620 \mathrm{~nm})$ emissions and are shown in Figure 6. We observe that upon monitoring the dabpdc ${ }^{2-}$ ligand emission, the excitation spectrum of 6 is dominated by the absorption features of the $\mathrm{bpdc}^{2-}$ chromophore, while monitoring at the $\mathrm{Eu}^{3+}$ emission results in an excitation spectrum showing a relatively weak albeit clear shoulder at ca. 425 $\mathrm{nm}$ which tails off above $445 \mathrm{~nm}$. This spectral feature is attributed to the absorption of the dabpdc ${ }^{2-}$ chromophore [27] and indicates that the latter may also sensitize $\mathrm{Eu}^{3+}$ emission.

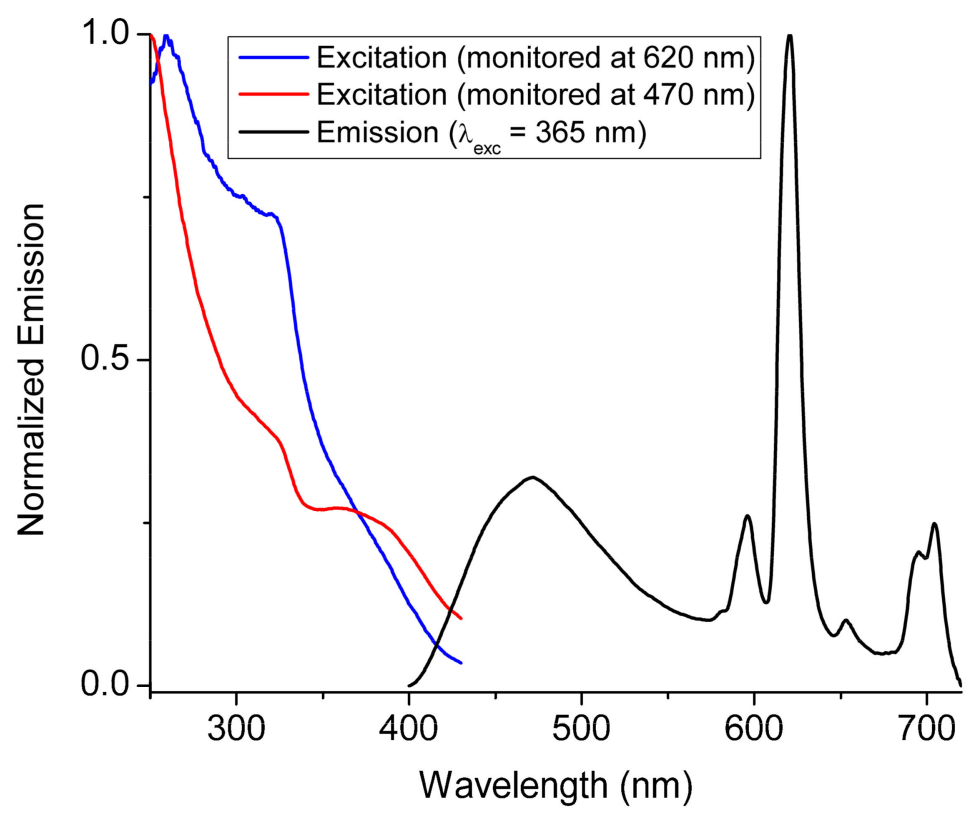

Figure 6. The solid-state emission and excitation spectra of compound 6 . The excitation spectra are monitored both at the dabpdc ${ }^{2-}(470 \mathrm{~nm})$ fluorescence and the $\mathrm{Eu}^{3+}$ emission $(620 \mathrm{~nm})$. 
Starting from 2 and progressively doping the framework with increased levels of $\mathrm{Eu}^{3+}$ (vide supra) results in increased lanthanide-based emission with a concomitant decrease of the contribution from the organic chromophore. The change in color of the materials doped with $10 \mathrm{~mol} \%$ of dabpdc ${ }^{2-}$ and increasing levels of $\mathrm{Eu}^{3+}(0-2.5 \mathrm{~mol} \%)$ is demonstrated by the CIE (Commission Internationale de l'Éclairage) coordinates of the chromaticity diagram of Figure 7, where we see that the emission color gradually shifts from the blue ( $x=0.172, y=0.173$ for 2$)$ to the purple-red region of the spectrum $(x=0.425, y=0.289$ for 8$)$. However, the absence of a strong yellow-green component in the emission spectra of this series of materials does not allow sufficient color tuning in order to achieve entry in the white region ( $x$ and $y$ values of 0.3 and above) [36]. Instead, a further increase of the $\mathrm{Eu}^{3+}$ doping levels results in the emission color traversing the purple region and eventually entering the red region.

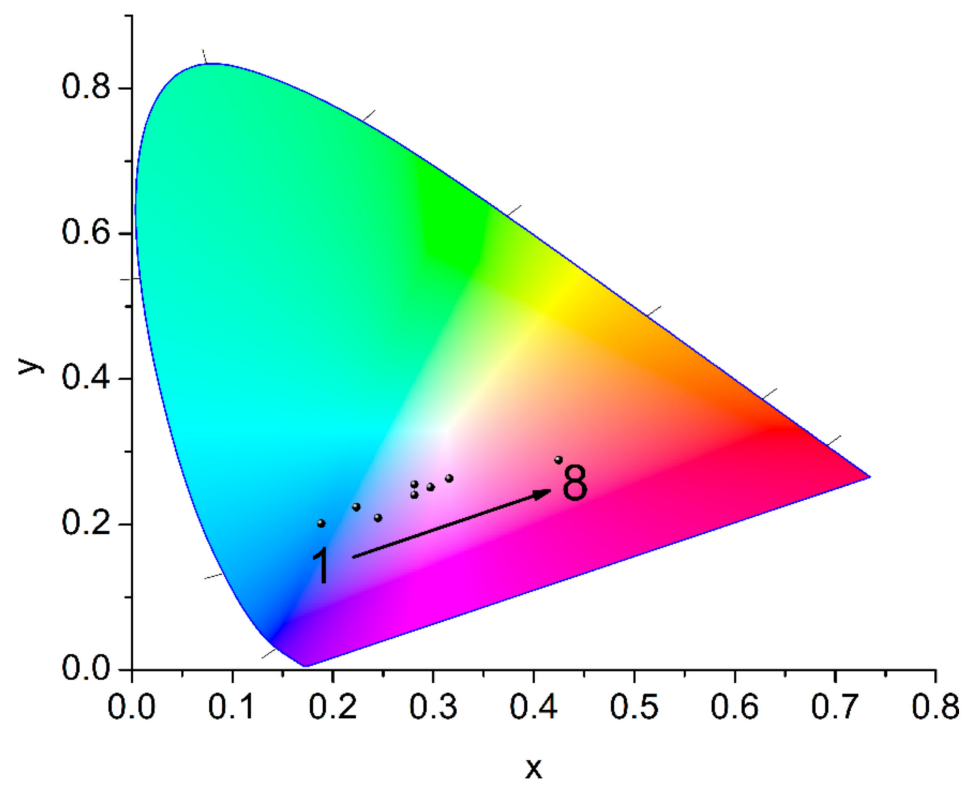

Figure 7. Chromaticity coordinates (CIE 1931) calculated from the corrected emission profiles of materials 1-8 showing the gradual shift from blue to red upon increasing the $\mathrm{Eu}^{3+}$ content.

Nonetheless, the presence of two clear emission components in 7 , arising from an organic chromophore and a lanthanide, prompted us to study the effect of temperature on its emission profile in order to explore the potential of the material to perform as a ratiometric luminescence thermometer [8,37-40]. Figure 8 shows the emission spectra of 7 at various temperatures from 80 to $300 \mathrm{~K}$. By examining the spectra of Figure 8, we observe that the ligand component shows a steady decrease in intensity with rising temperature while the $\mathrm{Eu}^{3+}$ luminophore shows distinctly different behavior in two different temperature regions. In the region between 80 and ca. $140 \mathrm{~K}$, we observe an increase of $\mathrm{Eu}^{3+}$ emission intensity, while in the region between 150 and $300 \mathrm{~K}$, the emission intensity of $\mathrm{Eu}^{3+}$ follows the steady decrease of that of the organic component. The decrease in the fluorescence intensity of the organic component as the temperature rises can be mainly attributed to the increasing participation of non-radiative pathways in the decay process of the dabpdc ${ }^{2-}$ chromophore [29]. The initial rise of the $\mathrm{Eu}^{3+}$ component between 80 and $150 \mathrm{~K}$ possibly indicates that, at that temperature range, ligand-to-metal energy transfer is a major non-radiative deactivation pathway for the dabpdc ${ }^{2-}$ excited state. At higher temperatures, increased molecular and lattice vibrations render thermal deactivation pathways dominant, and thereby lead to the observed reduction in the intensities of both the organic and $\mathrm{Eu}^{3+}$ emission components. 


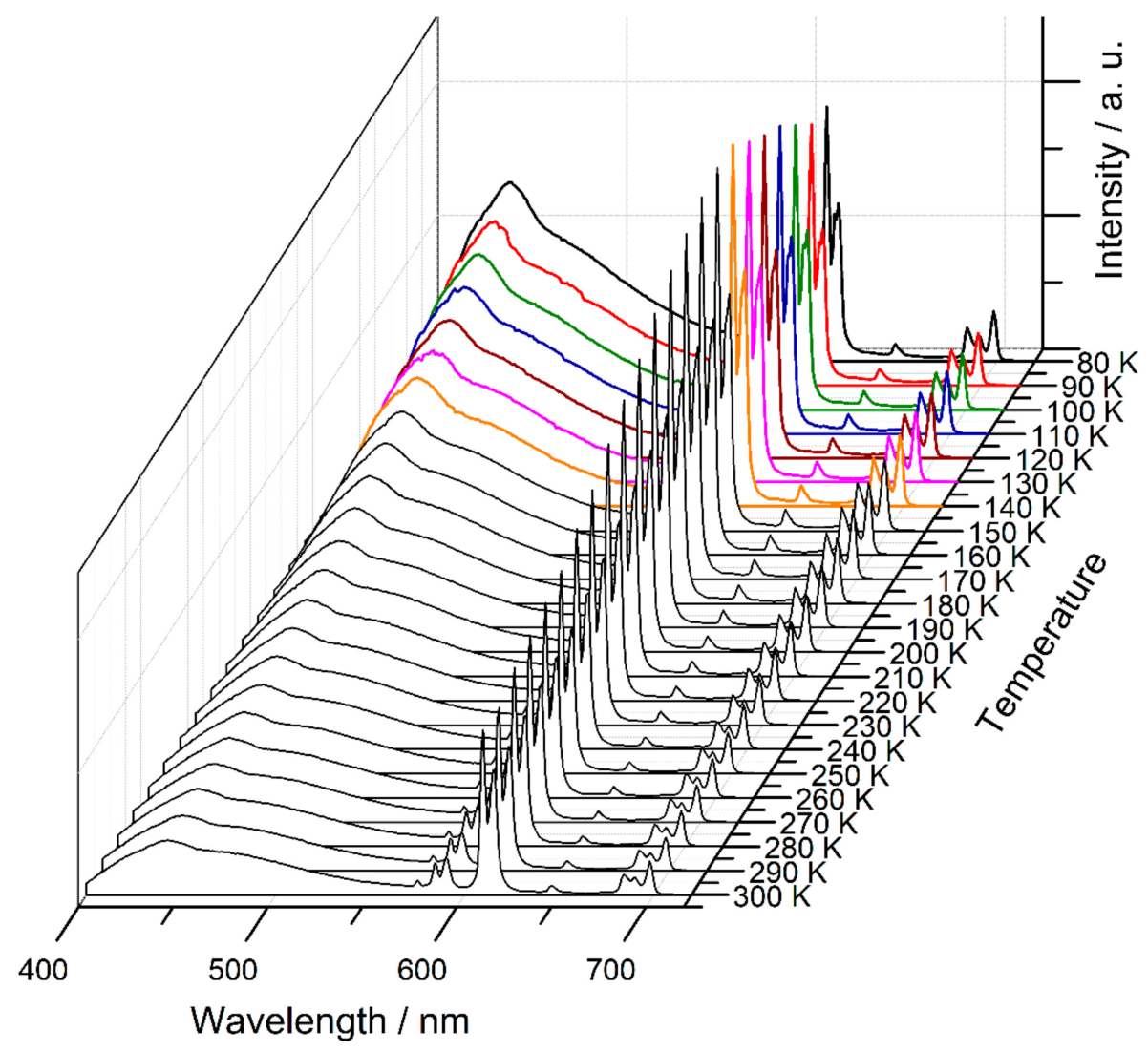

Figure 8. Temperature dependent emission spectra of 7 upon excitation at $375 \mathrm{~nm}$. The spectra in the temperature region between 80 and $140 \mathrm{~K}$ are highlighted to emphasize the increase in $\mathrm{Eu}^{3+}$-based emission with rising temperature (see main text).

If we define the ratio of the integrated intensities of the Eu ${ }^{3+}$-based ${ }^{5} \mathrm{D}_{0} \rightarrow{ }^{7} \mathrm{~F}_{2}$ emission peak $\left(I_{E u}\right)$ to the ligand-based fluorescence signal $\left(I_{L}\right)$ as the thermometric parameter $\Delta$ and plot the result against the temperature $T$, we obtain the diagram of Figure 9 . The data can be fitted satisfactorily (correlation coefficient $R^{2}=0.984$ ) to a second-degree polynomial (Equation (1)).

$$
\Delta=-1.05 \times 10^{-5} T^{2}+4.90 \times 10^{-3} T-0.21
$$

A

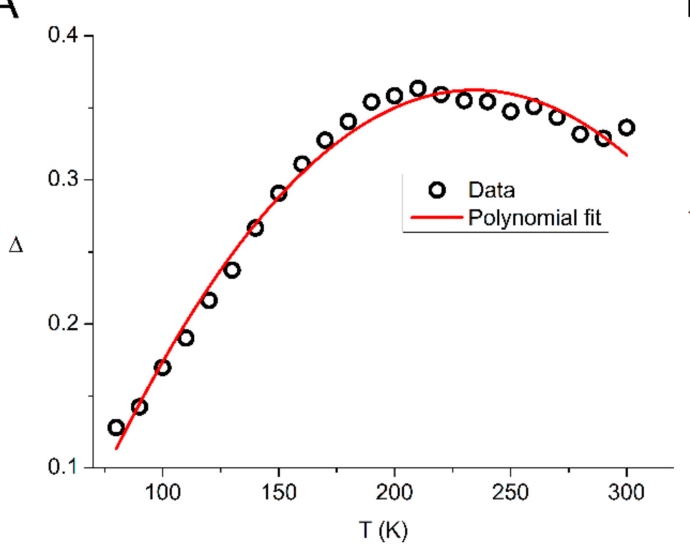

B

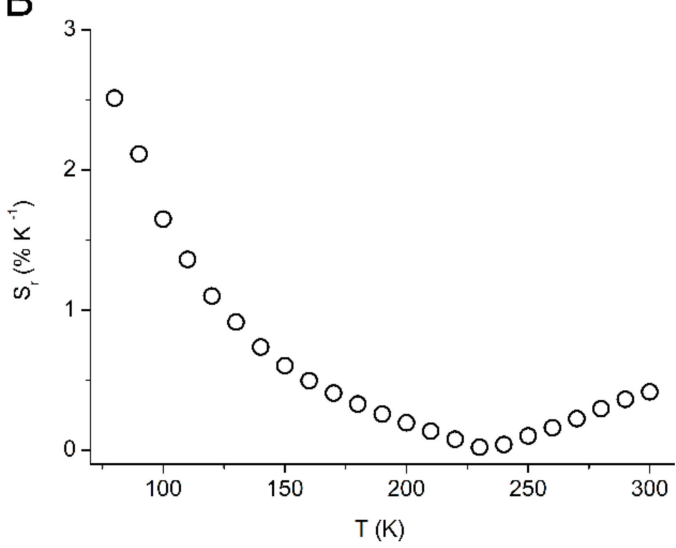

Figure 9. (A) The thermometric parameter versus temperature for material 7. The red line represents a polynomial fit to the experimental data. (B) The $S_{r}$ parameter versus temperature for material 7. See main text for details. 
The performance of a temperature sensor is often reported in terms of its relative sensitivity [41], $S_{r}$, which serves as a figure of merit to allow comparison between different temperature sensors reported in the literature and is defined in Equation (2) [8,42].

$$
S_{r}=\frac{1}{\Delta}\left|\frac{\partial \Delta}{\partial T}\right|
$$

The $S_{r}$ parameter of 7 as $\% \mathrm{~K}^{-1}$ is plotted against the temperature in Figure $9 \mathrm{~B}$. The maximum value of the relative sensitivity $S_{m}=2.51 \% \mathrm{~K}^{-1}$ is obtained at $80 \mathrm{~K}$. These results indicate that 7 can function as a ratiometric luminescence thermometer in the tested region from 80 to $300 \mathrm{~K}$ showing its best performance in the 80 to $150 \mathrm{~K}$ region. The maximum relative sensitivity of $2.51 \% \mathrm{~K}^{-1}$ shown by 7 compares well with the typical values obtained with many luminescent thermometers based on lanthanide organic frameworks [8-10,43]. Therefore, combined ligand and metal doping can be an effective route for the preparation of improved luminescent temperature sensors.

\section{Conclusions}

We demonstrated that the parent framework of [La(bpdc)Cl(DMF)] (1) [13] can be easily doped with the bridging ligand, dabpdc ${ }^{2-}$ (the diamino derivative of bpdc ${ }^{2-}$ ligand present in 1), and $\mathrm{Eu}^{3+}$ to produce a range of mixed ligand and mixed metal analogues. Doping of ca. $10 \mathrm{~mol} \%$ with dabpdc ${ }^{2-}(2)$ results in a moderate red shift of the ligand-based fluorescence due to interligand photoinduced energy transfer. Further doping with various amounts of $\mathrm{Eu}^{3+}$ yields materials which display sensitized $\mathrm{Eu}^{3+}$ emission along with the blue dabpdc ${ }^{2-}$ fluorescence. Emission color tuning was achieved by varying the $\mathrm{Eu}^{3+}$ doping percentage from 0 to $2.5 \mathrm{~mol} \%$, from blue to red through purple. However, the absence of a yellow-green component in the emission spectra of this series did not allow the achievement of white light luminescence. Finally, we studied the temperature dependence of the emission profile of $7\left(10 \mathrm{~mol} \%\right.$ dabdc $\left.^{2-}, 2.5 \mathrm{~mol} \% \mathrm{Eu}^{3+}\right)$ in the region from 80 to $300 \mathrm{~K}$. While the ligand component shows a steady decrease in fluorescence intensity with increasing temperature, the $\mathrm{Eu}^{3+}$ luminescence shows an initial enhancement from 80 to ca. $150 \mathrm{~K}$ before following the trend of the organic portion of the emission spectrum of 7 . We attribute the initial enhancement of Eu ${ }^{3+}$ luminescence to the dominance of ligand-to-metal energy transfer over thermal decay pathways at relatively low temperatures. Compound 7 shows good potential as a ratiometric luminescence thermometer displaying its best performance in the 80 to $150 \mathrm{~K}$ region with maximum sensitivity of $2.51 \% \mathrm{~K}^{-1}$ at $80 \mathrm{~K}$. This result shows that combined ligand and metal doping can be a viable route to produce new luminescence-based temperature sensors. Our group is currently working towards the construction of mixed lanthanide-organic frameworks exhibiting white luminescence and luminescence-based temperature sensing properties by following the above described strategy. The results obtained from the current study can be a stepping-stone towards the construction of superior optical materials.

\section{Materials and Methods}

\subsection{Synthesis}

Starting materials and solvents were purchased from the usual commercial sources (Sigma-Aldrich and Alfa Aesar) and were used as received.

\subsubsection{Synthesis of $\mathrm{H}_{2}$ dabpdc}

Dimethyl-2,2'-dinitro-[1,1'-biphenyl]-4,4'-dicarboxylate. Dimethyl-biphenyl-4,4'-dicarboxylate ( $1.00 \mathrm{~g}, 3.7 \mathrm{mmol})$ was added into concentrated $\mathrm{H}_{2} \mathrm{SO}_{4}(10 \mathrm{~mL})$. The mixture was stirred at room temperature for $10 \mathrm{~min}$. Nitric acid $\left(760 \mu \mathrm{L}, 3\right.$ eq.) was added into concentrated $\mathrm{H}_{2} \mathrm{SO}_{4}(2 \mathrm{~mL})$. This solution was added dropwise into the first mixture at room temperature over a period of $20 \mathrm{~min}$. The mixture was stirred at room temperature for $4 \mathrm{~h}$ and then poured into ice $(300 \mathrm{~mL})$ to form a beige 
solid. The resulting solid was dissolved in dichloromethane and the aqueous phase was extracted with dichloromethane $(3 \times 70 \mathrm{~mL})$. The combined organic layers were dried over $\mathrm{Na}_{2} \mathrm{SO}_{4}$ and evaporated under reduced pressure to afford a beige solid. The crude mixture was recrystallized from 2-propanol and washed with diethyl ether to give the pure product. Yield: $1.2 \mathrm{~g}(3.33 \mathrm{mmol}, 90 \%) .{ }^{1} \mathrm{H} \mathrm{NMR}$ $\left(500 \mathrm{MHz}, \mathrm{CDCl}_{3}\right): \delta(\mathrm{ppm}): 8.90(\mathrm{~s}, 2 \mathrm{H}), 8.37(\mathrm{~d}, J=8.4 \mathrm{~Hz}, 2 \mathrm{H}), 7.40(\mathrm{~d}, J=8 \mathrm{~Hz}, 2 \mathrm{H}), 4.02(\mathrm{~s}, 6 \mathrm{H})$.

Dimethyl-2,2'-diamino-[1,1'-biphenyl]-4,4'-dicarboxylate. Dimethyl-2,2'-dinitro-[1,1'-biphenyl]$4,4^{\prime}$-dicarboxylate $(1.2 \mathrm{~g}, 3.33 \mathrm{mmol})$ was dissolved in $20 \mathrm{~mL}$ acetic acid and the solution was stirred under Ar atmosphere for $10 \mathrm{~min}$. To this solution was added iron powder ( $3.7 \mathrm{~g}, 10 \mathrm{eq}$.) and the resulting mixture was stirred at room temperature for $24 \mathrm{~h}$. The suspension was filtered through celite, washed with $40 \mathrm{~mL}$ acetic acid and the filtrate was concentrated under reduced pressure. The solid was dissolved in ethyl acetate $(80 \mathrm{~mL})$ and was extracted with saturated aqueous sodium carbonate solution $(2 \times 80 \mathrm{~mL})$ and $\mathrm{H}_{2} \mathrm{O}(3 \times 80 \mathrm{~mL})$. The combined organic layers were dried over $\mathrm{Na}_{2} \mathrm{SO}_{4}$ and the solution was evaporated under vacuum to yield the product as a yellow solid. Yield $900 \mathrm{mg}$ (3 mmol, 90\%). ${ }^{1} \mathrm{H}$ NMR (500 MHz, DMSO- $\left.d_{6}\right): \delta(\mathrm{ppm}): 7.42(\mathrm{~s}, 2 \mathrm{H}), 7.21(\mathrm{~d}, J=7.8 \mathrm{~Hz}, 2 \mathrm{H}), 7.06(\mathrm{~d}$, $J=7.8 \mathrm{~Hz}, 2 \mathrm{H}), 4.97(\mathrm{~s}, 4 \mathrm{H}), 3.81(\mathrm{~s}, 6 \mathrm{H})$.

2,2'-Diamino-[1,1'-biphenyl]-4,4'-dicarboxylic acid ( $\mathrm{H}_{2}$ dabpdc). Dimethyl 2,2'-diamino[1,1'-biphenyl]-4,4'-dicarboxylate $(900 \mathrm{mg}, 3.0 \mathrm{mmol})$ was dissolved in THF $(20 \mathrm{~mL})$ and $20 \mathrm{~mL}$ of aqueous $\mathrm{NaOH}(0.6 \mathrm{M})$ were added dropwise under vigorous stirring. The mixture was stirred overnight at room temperature. The organic solvent was removed under vacuum and the aqueous solution was acidified with acetic acid to yield a light brown solid (735 mg, $2.7 \mathrm{mmol}, 90 \%) .{ }^{1} \mathrm{H}-\mathrm{NMR}$ $\left(500 \mathrm{MHz}, \mathrm{DMSO}-d_{6}\right): \delta(\mathrm{ppm})=12.64(\mathrm{br}, 2 \mathrm{H}), 7.40(\mathrm{~s}, 2 \mathrm{H}), 7.20(\mathrm{~d}, J=7.6 \mathrm{~Hz}, 2 \mathrm{H}), 7.40(\mathrm{~d}, J=7.8 \mathrm{~Hz}$, $2 \mathrm{H}), 4.90(\mathrm{br}, 4 \mathrm{H})$.

\subsubsection{Synthesis of MOFs}

Synthesis of $[\mathrm{La}(\mathrm{bpdc}) \mathrm{Cl}(\mathrm{DMF})] \quad(\mathbf{1}) . \quad \mathrm{LaCl}_{3} \cdot 7 \mathrm{H}_{2} \mathrm{O} \quad(74.8 \mathrm{mg}, \quad 0.2 \mathrm{mmol})$ and biphenyl-4,4'-dicarboxylic acid $(48.4 \mathrm{mg}, 0.2 \mathrm{mmol}$ ) were added in DMF $(3 \mathrm{~mL})$ and stirred until the solids were fully dissolved. The resulting solution was sealed in a screw cap $23 \mathrm{~mL}$ scintillation vial and placed in a preheated oven at $110{ }^{\circ} \mathrm{C}$ where it remained undisturbed for $24 \mathrm{~h}$ before being cooled to room temperature. Colorless needle-like crystals were isolated by filtration, washed with DMF $(5 \times 3 \mathrm{~mL})$, and dried under vacuum overnight. Yield $32 \mathrm{mg}(45 \%)$.

Synthesis of the $\left[\mathrm{La}_{1-x} \mathrm{Eu}_{\mathrm{x}}(\mathrm{bpdc})_{1-\mathrm{y}}\left(\right.\right.$ dabpdc) $\mathrm{y}$ Cl(DMF)] series. $\mathrm{LaCl}_{3} \cdot 7 \mathrm{H}_{2} \mathrm{O}(74.8 \mathrm{mg}, 0.2 \mathrm{mmol})$ and biphenyl-4,4'-dicarboxylic acid $(48.4 \mathrm{mg}, 0.2 \mathrm{mmol})$ were added in DMF $(3 \mathrm{~mL})$ and stirred until the solids were fully dissolved. Standard solutions of $\mathrm{EuCl}_{3} \cdot 6 \mathrm{H}_{2} \mathrm{O}\left(10^{-2} \mathrm{M}\right)$ and $\mathrm{H}_{2}$ dabdc $\left(10^{-2} \mathrm{M}\right)$ in DMF were prepared and calculated volumes were added in the reaction feed using a volumetric pipette, while the mixture was magnetically stirred, to achieve the desired $\mathrm{La}^{3+} / \mathrm{Eu}^{3+}$ and $\mathrm{H}_{2} \mathrm{bpdc} / \mathrm{H}_{2}$ dabpdc molar ratio. Otherwise, the procedure was identical to that for the synthesis of $\mathbf{1}$. Colorless or pale-yellow needle-like crystals were isolated by filtration, washed with DMF $(5 \times 3 \mathrm{~mL})$ and dried under vacuum overnight. Exact percentages of $\mathrm{Eu}^{3+}$ and $\mathrm{dabpdc}^{2-}$ in each doped analogue and reaction yields are shown in Table 1.

Table 1. Percentages of $\mathrm{H}_{2}$ dabpdc and $\mathrm{Eu}^{3+}$ doping ${ }^{1}$ and yields.

\begin{tabular}{|c|c|c|c|}
\hline Compound & $\mathrm{mol} \% \mathrm{H}_{2}$ dabpdc & $\mathrm{mol} \% \mathrm{Eu}^{3+}$ & Yield \\
\hline 2 & 10 & 0 & 42 \\
\hline 3 & 10 & 1.00 & 41 \\
\hline 4 & 10 & 1.50 & 40 \\
\hline 5 & 10 & 1.75 & 45 \\
\hline 6 & 10 & 2.00 & 41 \\
\hline 7 & 10 & 2.50 & 44 \\
\hline 8 & 0 & 1.75 & 39 \\
\hline 9 & 33 & 0 & 32 \\
\hline
\end{tabular}




\subsection{Physical Measurements and Crystallogtraphy}

Photoluminescence spectra. The emission spectra were measured on a Horiba fluorescence spectrometer equipped with a powder sample holder. The light source was a 450 W Xenon Arc Lamp (220-1000 nm) and the detector a red sensitive Hamamatsu R928 photomultiplier tube. All spectra were corrected for instrument response using the correction function generated after calibration of the instrument with a standard light source. Appropriate long pass filters were used to remove scattering from the sample and the monochromators. Temperature-dependent photoluminescence measurements were carried out in the 80-300 K range by placing the samples in the cold finger of a Janis VPF liquid nitrogen optical cryostat.

${ }^{1} \mathrm{H}-\mathrm{NMR} .{ }^{1} \mathrm{H}-\mathrm{NMR}$ spectra were recorded at room temperature on NMR Agilent $500 \mathrm{MHz}$, with the use of the solvent proton as an internal standard and on an Avance Brucker NMR spectrometer (500 MHz).

PXRD measurements. PXRD diffraction patterns were recorded on a Shimadzu 6000 Series X-ray diffractometer with a $\mathrm{Cu} \mathrm{K} \alpha$ source $(\lambda=1.5418 \AA)$.

$X$-ray Crystal Structure Determination. Single crystal X-ray diffraction data were collected on a Rigaku Oxford-Diffraction Supernova diffractometer, equipped with a CCD area detector utilizing $\mathrm{Cu}$ $\mathrm{K} \alpha(\lambda=1.5418 \AA)$ radiation. A suitable crystal was mounted on a Hampton cryoloop with Paratone-N oil and transferred to a goniostat where it was cooled for data collection. Empirical absorption corrections (multiscan based on symmetry-related measurements) were applied using CrysAlis RED software [44]. The structure was solved by direct methods using SIR2004 [45] and refined on $\mathrm{F}^{2}$ using full-matrix least-squares with SHELXL-2014/7 [46] within the WinGX [47] platform. Software packages used were as follows: CrysAlis CCD for data collection [44], CrysAlis RED for cell refinement and data reduction [44], and MERCURY [48] for molecular graphics. The non-H atoms were treated anisotropically, except for those that belong to disordered parts. The aromatic $\mathrm{H}$ atoms were placed in calculated, ideal positions and refined depending on their respective carbon atoms. Selected crystal data for 9 are summarized in Table S2.

Thermogravimetric Analysis (TGA). Thermal stability studies were performed with a Shimadzu TGA 50 thermogravimetric analyzer. Thermal analysis was conducted from 25 to $800{ }^{\circ} \mathrm{C}$ under air with a heating rate of $10^{\circ} \mathrm{C} \mathrm{min}^{-1}$.

Supplementary Materials: The following are available online, Table S1: Selected bond lengths and angles for 1., Table S2: Crystal and refinement data for 9, Figure S1: 1H-NMR spectrum of a digested sample of 2 in D2O/NaOH., Figure S2: The TGA curve for 1, Figure S3: The TGA curve for 2.

Author Contributions: T.L. designed research and wrote the paper; D.A. and S.A.D. preformed the syntheses; D.A., A.Z., N.P., A.J.T., G.I. and T.L. contributed in photophysical studies, structural characterization and data interpretation. All authors have read and agreed to the published version of the manuscript.

Funding: This research is co-financed by Greece and the European Union (European Social Fund-ESF) through the Operational Programme «Human Resources Development, Education and Lifelong Learning» in the context of the project "Strengthening Human Resources Research Potential via Doctorate Research-2nd Cycle" (MIS-5000432), implemented by the State Scholarships Foundation (IK $\Upsilon$ ).

Acknowledgments: S.A.D. wishes to thank the IKY foundation for a $\mathrm{PhD}$ scholarship.

Conflicts of Interest: The authors declare no conflict of interest.

\section{References}

1. Bünzli, J.-C.G. Chapter 287-Lanthanide Luminescence: From a Mystery to Rationalization, Understanding, and Applications. In Handbook on the Physics and Chemistry of Rare Earths; Bünzli, J.-C.G., Pecharsky, V.K., Eds.; Elsevier: Amsterdam, The Netherlands, 2016; Volume 50, pp. 141-176.

2. Bünzli, J.-C.G. On the design of highly luminescent lanthanide complexes. Coord. Chem. Rev. 2015, 293, 19-47. [CrossRef] 
3. Aletti, A.B.; Gillen, D.M.; Gunnlaugsson, T. Luminescent/colorimetric probes and (chemo-) sensors for detecting anions based on transition and lanthanide ion receptor/binding complexes. Coord. Chem. Rev. 2018, 354, 98-120. [CrossRef]

4. Armelao, L.; Quici, S.; Barigelletti, F.; Accorsi, G.; Bottaro, G.; Cavazzini, M.; Tondello, E. Design of luminescent lanthanide complexes: From molecules to highly efficient photo-emitting materials. Coord. Chem. Rev. 2010, 254, 487-505. [CrossRef]

5. Bünzli, J.-C.G.; Piguet, C. Taking advantage of luminescent lanthanide ions. Chem. Soc. Rev. 2005, 34, 1048-1077. [CrossRef] [PubMed]

6. Dramicanin, M.D. Sensing temperature via downshifting emissions of lanthanide-doped metal oxides and salts. A review. Methods Appl. Fluoresc. 2016, 4, 042001. [CrossRef]

7. Cui, Y.J.; Zhu, F.L.; Chen, B.L.; Qian, G.D. Metal-organic frameworks for luminescence thermometry. Chem. Commun. 2015, 51, 7420-7431. [CrossRef]

8. Rocha, J.; Brites, C.D.S.; Carlos, L.D. Lanthanide Organic Framework Luminescent Thermometers. Chem. Eur. J. 2016, 22, 14782-14795. [CrossRef]

9. Abdelhameed, R.M.; Ananias, D.; Silva, A.M.S.; Rocha, J. Luminescent Nanothermometers Obtained by Post-Synthetic Modification of Metal-Organic Framework MIL-68. Eur. J. Inorg. Chem. 2019, 2019, 1354-1359. [CrossRef]

10. Zhao, D.; Yue, D.; Jiang, K.; Zhang, L.; Li, C.; Qian, G. Isostructural $\mathrm{Tb}^{3+} / \mathrm{Eu}^{3+}$ Co-Doped Metal-Organic Framework Based on Pyridine-Containing Dicarboxylate Ligands for Ratiometric Luminescence Temperature Sensing. Inorg. Chem. 2019, 58, 2637-2644. [CrossRef]

11. D’Vries, R.F.; Alvarez-Garcia, S.; Snejko, N.; Bausa, L.E.; Gutierrez-Puebla, E.; de Andres, A.; Monge, M.A. Multimetal rare earth MOFs for lighting and thermometry: Tailoring color and optimal temperature range through enhanced disulfobenzoic triplet phosphorescence. J. Mater. Chem. C 2013, 1, 6316-6324. [CrossRef]

12. Cui, Y.J.; Song, R.J.; Yu, J.C.; Liu, M.; Wang, Z.Q.; Wu, C.D.; Yang, Y.; Wang, Z.Y.; Chen, B.L.; Qian, G.D. Dual-Emitting MOF superset of Dye Composite for Ratiometric Temperature Sensing. Adv. Mater. 2015, 27, 1420-1425. [CrossRef] [PubMed]

13. Jia, L.-N.; Hou, L.; Wei, L.; Jing, X.-J.; Liu, B.; Wang, Y.-Y.; Shi, Q.-Z. Five sra Topological Ln(III)-MOFs Based on Novel Metal-Carboxylate/Cl Chain: Structure, Near-Infrared Luminescence and Magnetic Properties. Cryst. Growth Des. 2013, 13, 1570-1576. [CrossRef]

14. Han, Y.-F.; Zhou, X.-H.; Zheng, Y.-X.; Shen, Z.; Song, Y.; You, X.-Z. Syntheses, structures, photoluminescence, and magnetic properties of nanoporous 3D lanthanide coordination polymers with $4,4^{\prime}$-biphenyldicarboxylate ligand. CrystEngComm 2008, 10, 1237-1242. [CrossRef]

15. Amghouz, Z.; García-Granda, S.; García, J.R.; Ferreira, R.A.S.; Mafra, L.; Carlos, L.D.; Rocha, J. Series of Metal Organic Frameworks Assembled from Ln(III), Na(I), and Chiral Flexible-Achiral Rigid Dicarboxylates Exhibiting Tunable UV-vis-IR Light Emission. Inorg. Chem. 2012, 51, 1703-1716. [CrossRef] [PubMed]

16. Chatenever, A.R.K.; Warne, L.R.; Matsuoka, J.E.; Wang, S.J.; Reinheimer, E.W.; LeMagueres, P.; Fei, H.; Song, X.; Oliver, S.R.J. Isomorphous Lanthanide Metal-Organic Frameworks Based on Biphenyldicarboxylate: Synthesis, Structure, and Photoluminescent Properties. Cryst. Growth Des. 2019, 19, 4854-4859. [CrossRef]

17. Horrocks, W.D.; Sudnick, D.R. Lanthanide ion probes of structure in biology. Laser-induced luminescence decay constants provide a direct measure of the number of metal-coordinated water molecules. J. Am. Chem. Soc. 1979, 101, 334-340. [CrossRef]

18. Gao, M.-L.; Wang, W.-J.; Liu, L.; Han, Z.-B.; Wei, N.; Cao, X.-M.; Yuan, D.-Q. Microporous Hexanuclear Ln(III) Cluster-Based Metal-Organic Frameworks: Color Tunability for Barcode Application and Selective Removal of Methylene Blue. Inorg. Chem. 2017, 56, 511-517. [CrossRef]

19. Wang, J.; Lu, G.; Liu, Y.; Wu, S.-G.; Huang, G.-Z.; Liu, J.-L.; Tong, M.-L. Building Block and Directional Bonding Approaches for the Synthesis of $\left\{\mathrm{DyMn}_{4}\right\} \mathrm{n}(\mathrm{n}=2,3)$ Metallacrown Assemblies. Cryst. Growth Des. 2019, 19, 1896-1902. [CrossRef]

20. Volkringer, C.; Marrot, J.; Férey, G.; Loiseau, T. Hydrothermal Crystallization of Three Calcium-Based Hybrid Solids with 2,6-Naphthalene- or 4,4'-Biphenyl-Dicarboxylates. Cryst. Growth Des. 2008, 8, 685-689. [CrossRef]

21. Qiao, Y.; Li, Z.-M.; Wang, X.-B.; Guan, W.-S.; Liu, L.-H.; Liu, B.; Wang, J.-K.; Che, G.-B.; Liu, C.-B.; Lin, X. Thermal behaviors and adsorption properties of two Europium(III) complexes based on 2-(4-carboxyphenyl) imidazo [4, 5-f]-1,10-phenanthroline. Inorg. Chim. Acta 2018, 471, 397-403. [CrossRef] 
22. Yan, W.; Zhang, C.; Chen, S.; Han, L.; Zheng, H. Two Lanthanide Metal-Organic Frameworks as Remarkably Selective and Sensitive Bifunctional Luminescence Sensor for Metal Ions and Small Organic Molecules. ACS Appl. Mater. Interfaces 2017, 9, 1629-1634. [CrossRef] [PubMed]

23. Zhou, J.-M.; Shi, W.; Li, H.-M.; Li, H.; Cheng, P. Experimental Studies and Mechanism Analysis of High-Sensitivity Luminescent Sensing of Pollutional Small Molecules and Ions in Ln4O4 Cluster Based Microporous Metal-Organic Frameworks. J. Phys. Chem. C 2014, 118, 416-426. [CrossRef]

24. Zhang, S.; Yang, Y.; Xia, Z.-Q.; Liu, X.-Y.; Yang, Q.; Wei, Q.; Xie, G.; Chen, S.-P.; Gao, S.-L. Eu-MOFs with 2-(4-Carboxyphenyl) imidazo [4,5-f]-1,10-phenanthroline and Ditopic Carboxylates as Coligands: Synthesis, Structure, High Thermostability, and Luminescence Properties. Inorg. Chem. 2014, 53, 10952-10963. [CrossRef] [PubMed]

25. Min, Z.; Singh-Wilmot, M.A.; Cahill, C.L.; Andrews, M.; Taylor, R. Isoreticular Lanthanide Metal-Organic Frameworks: Syntheses, Structures and Photoluminescence of a Family of 3D Phenylcarboxylates. Eur. J. Inorg. Chem. 2012, 2012, 4419-4426. [CrossRef]

26. Liu, C.; Eliseeva, S.V.; Luo, T.-Y.; Muldoon, P.F.; Petoud, S.; Rosi, N.L. Near infrared excitation and emission in rare earth MOFs via encapsulation of organic dyes. Chem. Sci. 2018, 9, 8099-8102. [CrossRef]

27. Diamantis, S.A.; Pournara, A.D.; Hatzidimitriou, A.G.; Manos, M.J.; Papaefstathiou, G.S.; Lazarides, T. Two new alkaline earth metal organic frameworks with the diamino derivative of biphenyl-4,4'-dicarboxylate as bridging ligand: Structures, fluorescence and quenching by gas phase aldehydes. Polyhedron 2018, 153, 173-180. [CrossRef]

28. Dikhtiarenko, A.; Olivos Suarez Alma, I.; Pustovarenko, A.; García-Granda, S.; Gascon, J. Crystal structure of 2,2'-diamino-[1,1'-biphenyl]-4,4'-dicarboxylic acid dihydrate, $\mathrm{C}_{14} \mathrm{H}_{16} \mathrm{~N}_{2} \mathrm{O}_{6}$. Z. Kristallogr. NCS 2016, 231, 65-67. [CrossRef]

29. Lakowicz, J.R. Principles of Fluorescence Spectroscopy; Springer Science: New York, NY, USA, 2006.

30. Kent, C.A.; Mehl, B.P.; Ma, L.Q.; Papanikolas, J.M.; Meyer, T.J.; Lin, W.B. Energy Transfer Dynamics in Metal-Organic Frameworks. J. Am. Chem. Soc. 2010, 132, 12767-12769. [CrossRef]

31. Lin, J.X.; Hu, X.Q.; Zhang, P.; Van Rynbach, A.; Beratan, D.N.; Kent, C.A.; Mehl, B.P.; Papanikolas, J.M.; Meyer, T.J.; Lin, W.B.; et al. Triplet Excitation Energy Dynamics in Metal-Organic Frameworks. J. Phys. Chem. C 2013, 117, 22250-22259. [CrossRef]

32. So, M.C.; Wiederrecht, G.P.; Mondloch, J.E.; Hupp, J.T.; Farha, O.K. Metal-organic framework materials for light-harvesting and energy transfer. Chem. Commun. 2015, 51, 3501-3510. [CrossRef]

33. Son, H.J.; Jin, S.; Patwardhan, S.; Wezenberg, S.J.; Jeong, N.C.; So, M.; Wilmer, C.E.; Sarjeant, A.A.; Schatz, G.C.; Snurr, R.Q.; et al. Light-harvesting and ultrafast energy migration in porphyrin-based metal-organic frameworks. J. Am. Chem. Soc. 2013, 135, 862-869. [CrossRef] [PubMed]

34. Yu, J.; Park, J.; Van Wyk, A.; Rumbles, G.; Deria, P. Excited-State Electronic Properties in Zr-Based Metal-Organic Frameworks as a Function of a Topological Network. J. Am. Chem. Soc. 2018, 140, 10488-10496. [CrossRef] [PubMed]

35. Shavaleev, N.M.; Eliseeva, S.V.; Scopelliti, R.; Bünzli, J.-C.G. Influence of Symmetry on the Luminescence and Radiative Lifetime of Nine-Coordinate Europium Complexes. Inorg. Chem. 2015, 54, 9166-9173. [CrossRef]

36. Kotova, O.; Comby, S.; Lincheneau, C.; Gunnlaugsson, T. White-light emission from discrete heterometallic lanthanide-directed self-assembled complexes in solution. Chem. Sci. 2017, 8, 3419-3426. [CrossRef] [PubMed]

37. Cui, Y.J.; Xu, H.; Yue, Y.F.; Guo, Z.Y.; Yu, J.C.; Chen, Z.X.; Gao, J.K.; Yang, Y.; Qian, G.D.; Chen, B.L. A Luminescent Mixed-Lanthanide Metal-Organic Framework Thermometer. J. Am. Chem. Soc. 2012, 134, 3979-3982. [CrossRef] [PubMed]

38. Rao, X.T.; Song, T.; Gao, J.K.; Cui, Y.J.; Yang, Y.; Wu, C.D.; Chen, B.L.; Qian, G.D. A Highly Sensitive Mixed Lanthanide Metal-Organic Framework Self-Calibrated Luminescent Thermometer. J. Am. Chem. Soc. 2013, 135, 15559-15564. [CrossRef]

39. Li, L.; Zhu, Y.L.; Zhou, X.H.; Brites, C.D.S.; Ananias, D.; Lin, Z.; Paz, F.A.A.; Rocha, J.; Huang, W.; Carlos, L.D. Visible-Light Excited Luminescent Thermometer Based on Single Lanthanide Organic Frameworks. Adv. Funct. Mater. 2016, 26, 8677-8684. [CrossRef]

40. Liu, X.; Akerboom, S.; Jong, M.D.; Mutikainen, I.; Tanase, S.; Meijerink, A.; Bouwman, E. Mixed-Lanthanoid Metal-Organic Framework for Ratiometric Cryogenic Temperature Sensing. Inorg. Chem. 2015, 54, 11323-11329. [CrossRef] 
41. Wade, S.A.; Collins, S.F.; Baxter, G.W. Fluorescence intensity ratio technique for optical fiber point temperature sensing. J. Appl. Phys. 2003, 94, 4743-4756. [CrossRef]

42. Brites, C.D.S.; Lima, P.P.; Silva, N.J.O.; Millán, A.; Amaral, V.S.; Palacio, F.; Carlos, L.D. Thermometry at the nanoscale. Nanoscale 2012, 4, 4799-4829. [CrossRef]

43. Qiu, L.; Yu, C.; Wang, X.; Xie, Y.; Kirillov, A.M.; Huang, W.; Li, J.; Gao, P.; Wu, T.; Gu, X.; et al. Tuning the Solid-State White Light Emission of Postsynthetic Lanthanide-Encapsulated Double-Layer MOFs for Three-Color Luminescent Thermometry Applications. Inorg. Chem. 2019, 58, 4524-4533. [CrossRef] [PubMed]

44. CrysAlis CCD and CrysAlis RED; Oxford Diffraction Ltd: Abingdon, UK, 2008.

45. Burla, M.C.; Caliandro, R.; Camalli, M.; Carrozzini, B.; Cascarano, G.L.; Caro, L.D.; Giacovazzo, C.; Polidori, G.; Spagna, R.J. SIR2004: An improved tool for crystal structure determination and refinement. Appl. Crystallogr. 2005, 38, 381-388. [CrossRef]

46. Sheldrick, G.M. SHELXT-Integrated space-group and crystal-structure determination. Acta Cryst. 2015, C71, 3-8. [CrossRef] [PubMed]

47. Farrugia, L.J.J. J. WinGX and ORTEP for Windows: an update. Appl. Cryst. 2012, 45, 849-854. [CrossRef]

48. Macrae, C.F.; Edgington, P.R.; McCabe, P.; Pidcock, E.; Shields, G.P.; Taylor, R.; Towler, M.; van de Streek, J.J. Mercury: visualization and analysis of crystal structures. Appl. Cryst. 2006, 39, 453-457. [CrossRef]

Sample Availability: Samples of the compounds are available from the authors. 